\title{
Characterization of Oxygen Consumption in a Special Population: AFEAU (Urban Anti- terrorist Special Forces Group)
}

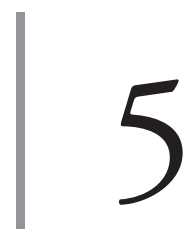

https://doi.org/10.21830/9789585380240.05

\author{
Angélica María Puentes Salazar ${ }^{1}$ \\ Oscar Mauricio Sarmiento Becerra ${ }^{2}$
}

\begin{abstract}
Cardiovascular endurance is one of the health-related components of fitness. A reliable way of evaluating it is by measuring the maximum oxygen consumption, "which represents the maximum amount of oxygen that the body is capable of absorbing, transporting, and consuming per unit of time" ${ }^{2}$. This parameter allows assessing adaptations to cardiovascular resistance training. It facilitates the comparison among individuals and populations based on factors, such as genetics, age, gender, body mass, and composition.

In this chapter, a cross-sectional study analyzes the results of oxygen consumption tests carried out with personnel from the Urban Antiterrorist Special Forces Group (AFEAU, for the term in Spanish) to characterize their cardiovascular condition. Subtle differences were found among the groups evaluated. The population from 2018 showed better results than in 2016; this generates new proposals for monitoring this population and options for expanding research in this field.
\end{abstract}

Keywords: ergospirometry, maximum oxygen consumption, cardio vascular resistance

1 Specialist in Physical Activity and Sports Medicine at Centro de investigación de la cultura física (CICFI)

2 Medical specialist in Physical Activity and Sports Medicine at Unidad de Ciencias Aplicadas al Deporte (UCAD). 


\section{Introduction}

This chapter shows how oxygen consumption is measured to determine cardiovascular endurance, one of the health-related components of fitness (1), through treadmill ergo-spirometry in a specific population within the armed forces, namely, the Urban Anti-terrorist Special Forces (AFEAU) group. The most important variable obtained from the physical test, maximum oxygen consumption, "which is the maximum amount of oxygen that the body is capable of absorbing, transporting and consuming per unit of time," must be clear (2). It is the product of maximum cardiac output (liters blood - minute $-1)$ and the difference in arteriovenous oxygen $(\mathrm{mL}$ of oxygen per liter of blood) (1).

Characterizing this population provides an objective measurement of its cardiovascular condition. It can also be used to compare with the results of oxygen consumption by ergo-spirometry in other military populations, given that the maximum oxygen consumption has been considered a means to evaluate adaptations to cardiovascular endurance training (3). Characteristics, like age, height, and weight, were included in the data analyzed to better understand this population. Ergospirometry reports served to evaluate oxygen consumption, heart rate, and maximum speed during the test. This data helped to evaluate the population's cardiovascular condition at different levels of training and provided valuable information for training programs.

Peak oxygen consumption is an indicator of an individual's functional capacity, which depends on several factors. Up to $70 \%$ depends on genetics, making it the most significant determinant. Other variables, like age, gender, and body mass and composition, can affect up to $50 \%$, and up to $20 \%$ can be improved by the degree of training or physical conditioning $(2,3)$. Expected values for men between 20 and 40 years of age were 35 to $45 \mathrm{ml} /$ $\mathrm{kg} / \mathrm{min}$, and, depending on the type of training, the range could be from 40 to $80 \mathrm{ml} / \mathrm{kg} / \mathrm{min}$ (2). Cardiac output is one of the components of oxygen consumption. It is the product of heart rate and systolic volume, both of which increase with physical activity. The heart rate response depends on age and training; the more training, the more significant the response (4). This was one of the variables measured during the ergospirometry test. 


\section{Methodology}

This study is a retrospective description of the results of a treadmill ergospirometry test with a progressive and incremental protocol, performed on two different groups during two different periods. The first four participants were measured in December 2016, the second group of five individuals in May 2018. These ergospirometry tests were performed in the laboratory of the Centro de Investigación de la Cultura Física (CICFI, for the term in Spanish) by the staff in the research group at Escuela Militar de Cadetes "General José María Córdova" in the city of Bogotá D.C. and interpreted by the sports physician in the research center. The tests completed fully by the members of the urban anti-terrorist special forces group (AFEAU) were included. One partially completed test from the 2018 group was excluded. The following variables were evaluated in these tests: oxygen consumption and heart rate at the threshold and maximum, and the maximum speed reached in the test. The equipment used was a Metalyzer 3B-R2 ergospirometer and an HP Cosmos treadmill. The Stata 13 statistical program was used to perform a descriptive analysis of the data. The data are shown as medians and interquartile ranges, given the small sample size.

\section{Results}

The oxygen consumption of nine members of the urban anti-terrorist task force during 2016 and 2018 was measured by using treadmill ergospirometry. Figure 1 shows the distribution of the number of individuals included.

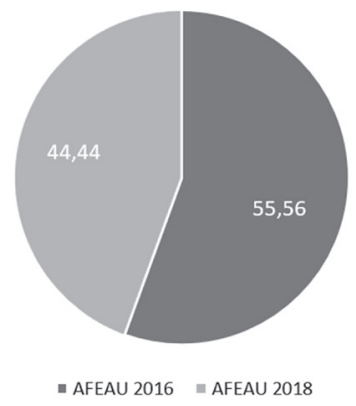

Figure 1. Distribution of the number of persons included in the percentages Source: Material created by the author. 
The median age of the participants was 34 (Interquartile range [IQR]: 31-34), their median height and weight were 1.69 meters (IQR: 1.66-1.72), and 69 kilograms (IQR: 66-72), respectively. Table 1 shows a summary of the basic characteristics of the study population, separated by year (2016 and 2018).

Table 1. Population characteristics

\begin{tabular}{cccccc}
\hline Year & Variable & Median & IQR $^{*}$ & Minimum & Maximum \\
\hline \multirow{2}{*}{2016} & Height $(\mathrm{m})$ & 1.68 & $1.63-1.73$ & 1.6 & 1.76 \\
& Weight $(\mathrm{kg})$ & 67.5 & $62.0-70.5$ & 58 & 72 \\
& Age (years) & 34 & $31.5-36.5$ & 29 & 39 \\
\multirow{2}{*}{2018} & Height $(\mathrm{m})$ & 1.69 & $1.66-1.72$ & 1.65 & 1.76 \\
& Weight (kg) & 69 & $67.0-74.0$ & 61 & 75 \\
& Age (years) & 33 & $31.0-34.0$ & 29 & 36 \\
\multirow{7}{*}{ Total } & Height (m) & 1.69 & $1.66-1.72$ & 1.6 & 1.76 \\
& Weight (kg) & 69 & $66.0-72.0$ & 58 & 75 \\
& Age (years) & 34 & $31.0-34.0$ & 29 & 39 \\
\hline
\end{tabular}

*IQR: Interquartile range. Source: Material created by the author.

The individuals measured in 2018 had a lower median age (Figure 2), but a higher median height (Figure 3) and weight (Figure 4).

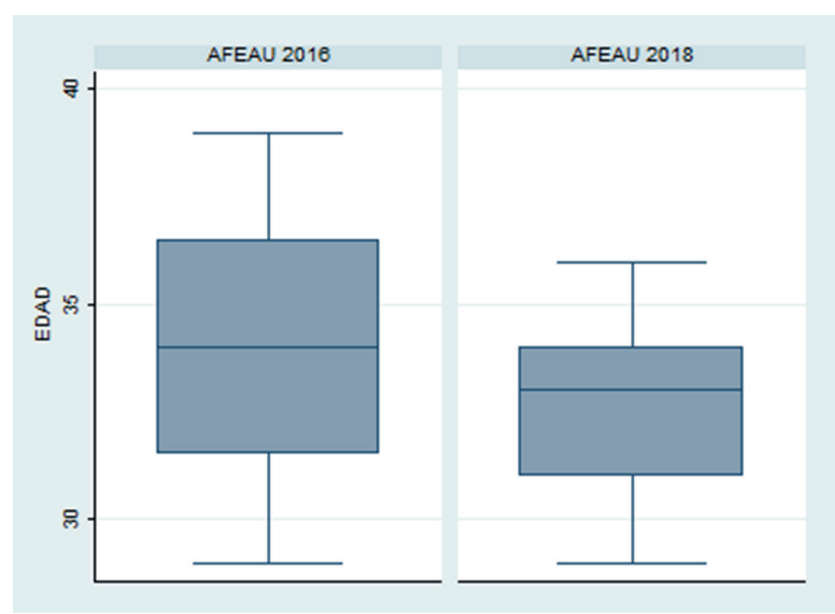

Figure 2. Age distribution (years) according to the year of the study. Source: Material created by the author. 


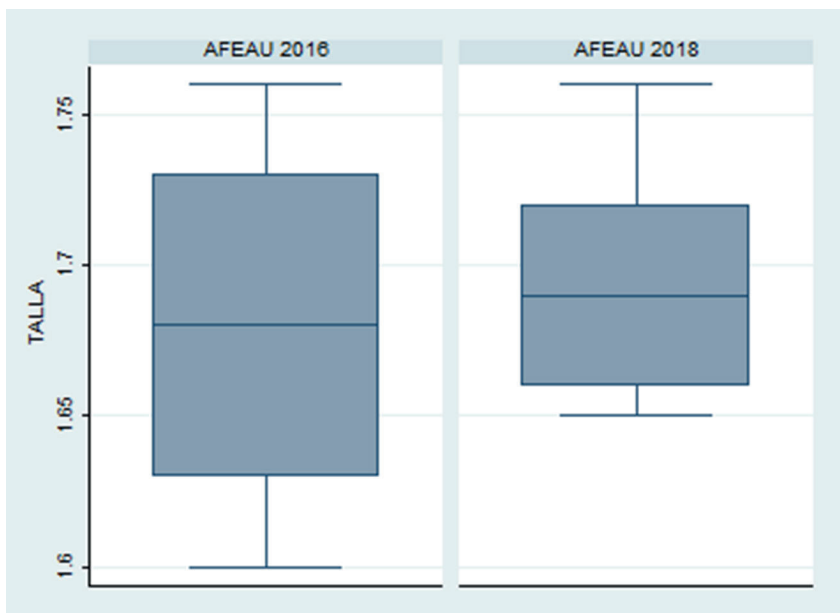

Figure 3. Height distribution (meters) according to the year of the study. Source: Material created by the author.

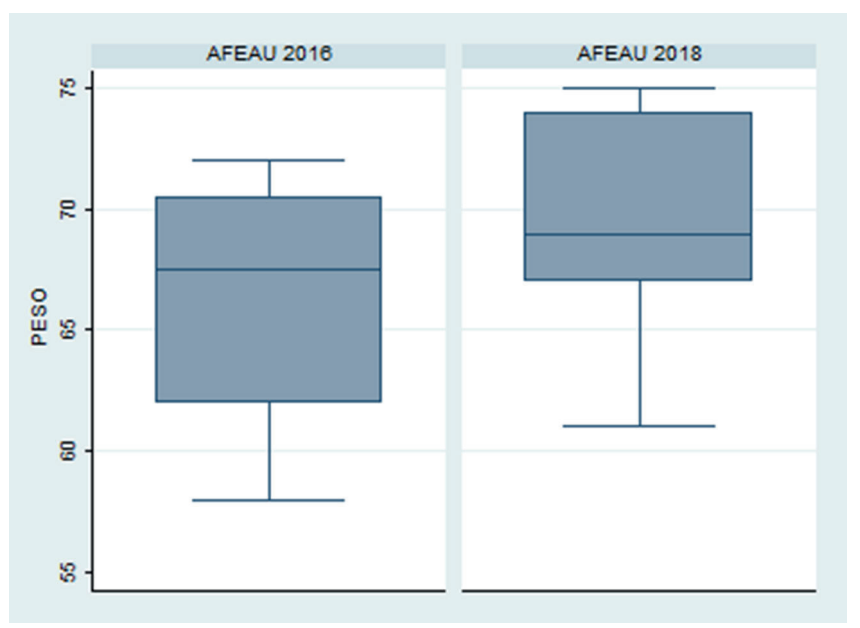

Figure 4. Weight distribution (kilograms) according to the year of the study. Source: Material created by the author.

Table 2 presents the results of oxygen consumption by ergo-spirometry respiratory condition measurement by clinical characteristics. Note here that the participants' average oxygen consumption at the threshold and maximum was 39 (IQR: 37-45) and 45 (IQR: $43-50) \mathrm{mL} / \mathrm{min} / \mathrm{kg}$, respec- 
tively. The median heart rate at the threshold was 155 bpm (IQR: 152-158). Meanwhile, the median of the maximum frequency reached $174 \mathrm{bpm}$ (IQR: 166-176). The maximum speed in the test was a median of $18.5 \mathrm{~km} / \mathrm{hr}$ (IQR: 18.5-20.1).

Table 2. Clinical Characteristics

\begin{tabular}{|c|c|c|c|c|c|}
\hline Year & Variable & Median & IQR & Minimum & Maximum \\
\hline \multirow[t]{5}{*}{2016} & $\mathrm{VO}_{2}$ threshold $(\mathrm{mL} / \mathrm{min} / \mathrm{kg})$ & 38 & $36.5-40.5$ & 36 & 42 \\
\hline & $\mathrm{VO}_{2}$ Maximum $(\mathrm{mL} / \mathrm{min} / \mathrm{kg})$ & 44.5 & $43.0-48.0$ & 42 & 51 \\
\hline & CF threshold (Ipm) & 158.5 & $152.0-169.0$ & 152 & 173 \\
\hline & CF Maximum (Ipm) & 176.5 & $166.5-179.0$ & 159 & 179 \\
\hline & Max. speed $(\mathrm{km} / \mathrm{h})$ & 18.5 & $18.5-19.3$ & 18.5 & 20.1 \\
\hline \multirow[t]{5}{*}{2018} & $\mathrm{VO}_{2}$ threshold $(\mathrm{mL} / \mathrm{min} / \mathrm{kg})$ & 45 & $37.0-46.0$ & 36 & 46 \\
\hline & $\mathrm{VO}_{2}$ Maximum $(\mathrm{mL} / \mathrm{min} / \mathrm{kg})$ & 48 & $43.0-50.0$ & 41 & 53 \\
\hline & CF threshold (bpm) & 155 & $152-158$ & 152 & 158 \\
\hline & CF Maximum (bpm) & 168 & $166.0-175.0$ & 159 & 176 \\
\hline & Max. speed $(\mathrm{km} / \mathrm{h})$ & 20.1 & $18.5-20.1$ & 16,9 & 20.1 \\
\hline \multirow[t]{5}{*}{ Total } & $\mathrm{VO}_{2}$ threshold $(\mathrm{mL} / \mathrm{min} / \mathrm{kg})$ & 39 & $37.0-45.0$ & 36 & 46 \\
\hline & $\mathrm{VO}_{2}$ Maximum $(\mathrm{mL} / \mathrm{min} / \mathrm{kg})$ & 45 & $43.0-50.0$ & 41 & 53 \\
\hline & CF threshold (bpm) & 155 & $152.0-158.0$ & 152 & 173 \\
\hline & CF Maximum (bpm) & 174 & $166.0-176.0$ & 159 & 179 \\
\hline & Max. speed $(\mathrm{km} / \mathrm{h})$ & 18.5 & $18.5-20.1$ & 16.9 & 20.1 \\
\hline
\end{tabular}

*IQR: Interquartile range. Source: Material created by the author

Compared with the 2016 participants, the 2018 group of participants had higher median values of oxygen consumption at the threshold (Figure 5) and maximum (Figure 6). 


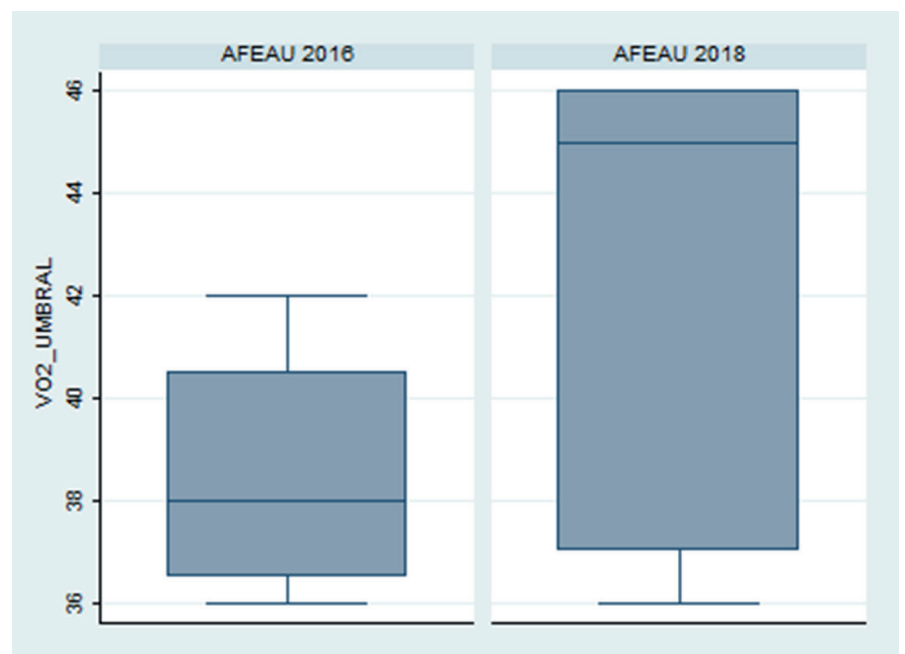

Figure 5. Distribution of threshold oxygen consumption $(\mathrm{mL} / \mathrm{min} / \mathrm{kg}$ ) according to the year of the study

Source: Material created by the author

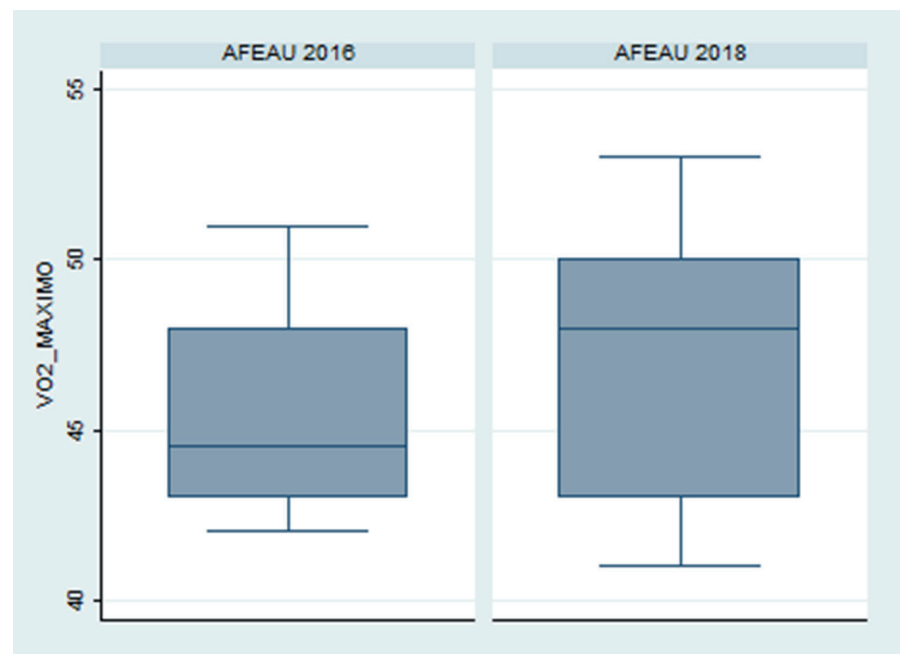

Figure 6. Distribution of maximum oxygen consumption $(\mathrm{mL} / \mathrm{min} / \mathrm{kg})$ according to the year of the study

Source: material created by the author

Additionally, the group of participants in 2016 obtained higher heart rate median values at the threshold (Figure 7 ) and maximum (Figure 8). 


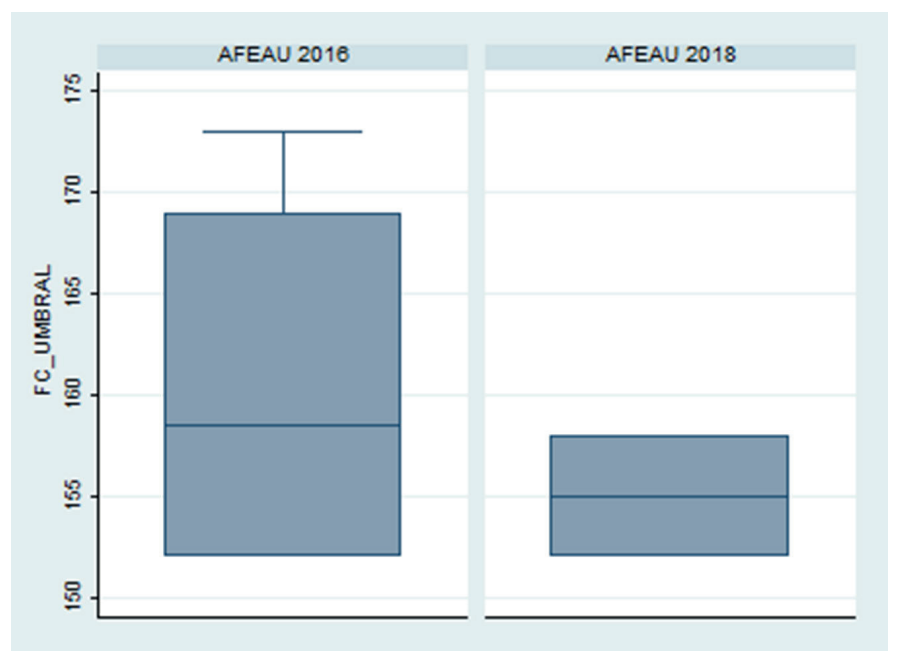

Figure 7. Threshold cardiac frequency (BPM) distribution according to the year of the study

Source: Material created by the author

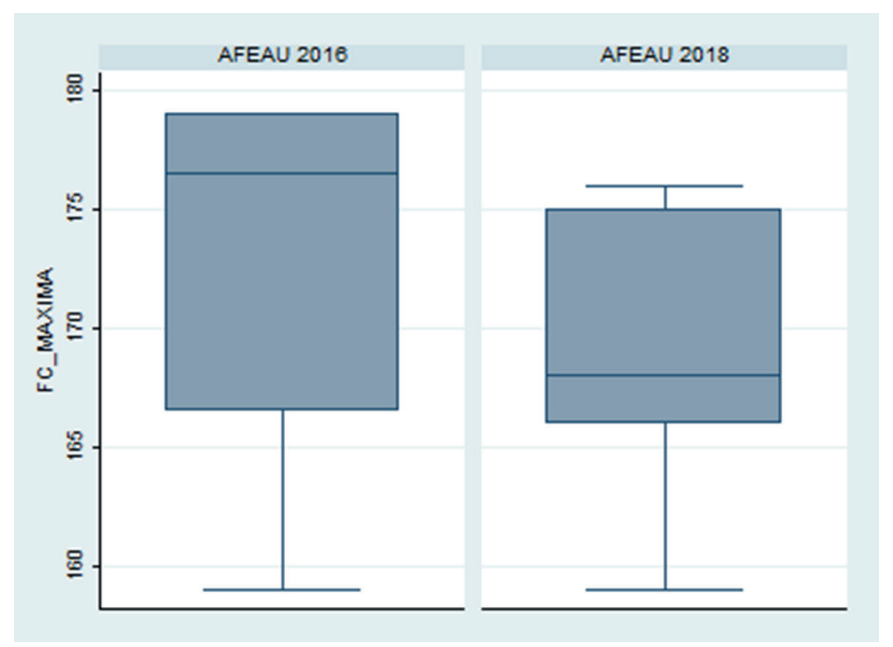

Figure 8. Distribution of the maximum heart rate (MHR) according to the year of the study

Source: Material created by the author

Another parameter evaluated with the data obtained from oxygen consumption and heart rate is the percentage of the maximum values at 
which the threshold was reached; this information helps in recommending training work to improve cardiovascular endurance.

In this study, the values of percentages of threshold oxygen consumption were all $>81 \%$. In the cardiac frequency variable, which is the most widely used to modify training because of its easy monitoring, the percentages of the maximum frequency in which the threshold was achieved were $>86 \%$; six of the nine measurements were $>90 \%$.

\section{Discussion}

The two groups evaluated shared similar ages, heights, and weights. Their results for maximum oxygen consumption by interquartile ranges were also similar; 43 - $48 \mathrm{~mL} / \mathrm{kg} / \mathrm{min}$ for the AFEAU 2016 group and 43 $50 \mathrm{~mL} / \mathrm{kg} / \mathrm{min}$ in the AFEAU 2018 group. The values were slightly above the expected ranges $(35-45 \mathrm{~mL} / \mathrm{kg} / \mathrm{min})$ for healthy men from 20 to 40 years of age (2). However, differences existed in the medians, $44.5 \mathrm{~mL} / \mathrm{kg} /$ min for the AFEAU 2016 group and $48 \mathrm{~mL} / \mathrm{kg} / \mathrm{min}$ for the AFEAU 2018, showing improved cardiovascular fitness in the 2018 group. Concerning the oxygen consumption at the threshold, which is the point of metabolic change between stable and unstable (5), a difference was evident in both medians and interquartile ranges. The 2016 AFEUA group had a median of $38 \mathrm{~mL} / \mathrm{kg} / \mathrm{min}$ and IQR of $36.5-40.5 \mathrm{~mL} / \mathrm{kg} / \mathrm{min}$, and the 2018 AFEUA group had a median of $45 \mathrm{~mL} / \mathrm{kg} / \mathrm{min}$ and IQR of $37-46 \mathrm{~mL} / \mathrm{kg} / \mathrm{min}$. This data supports the conclusion that the 2018 group had a superior cardiovascular condition. This quality is of utmost importance, given that this population's effective performance of its tasks involves different skills and capacities at the mental and physical levels. Therefore, it is acknowledged that adequate physical fitness at the cardiovascular level, as well as strength development programs $(6,7,8)$, can help them to fulfill their roles and objectives, challenging their training both in common tasks and in military competitions at international level $(7,8,9)$. 
The maximum and threshold oxygen consumption data are just one measurement in this population with already implemented specific training. However, without initial measurements prior to this type of training, the evaluation of the impact of the physical preparation received is limited. The results of before-and-after measurements used in a study involving a population performing compulsory military service showed that training could be deficient if resistance is to be improved in military personnel. It found that the $\mathrm{VO}_{2}$ maximum increased by $5 \%$ only in subjects with low initial $\mathrm{VO}_{2}$ maximum. No change was found in subjects with the median $\mathrm{VO}_{2}$ maximum, and it tended to decrease in those with a higher initial level (10). Unlike the aforementioned, another study reported significant improvement in $\mathrm{VO}_{2}$ maximum among 72 recruits when combining eight weeks of basic training with resistance or strength training (11).

Characterization of the military population and their training, as well as the importance of adequate physical condition, have been carried out in different countries, such as Canada, the Netherlands, the United Kingdom, and the United States (7). Therefore, describing the cardiovascular condition by measuring the maximum oxygen consumption through ergo-spirometry of a special population, like the Special Anti-Terrorist Forces Group, AFEAU, contributes to understanding the military population.

In conclusion, the results showed that, overall, the AFEAU has an adequate cardiovascular condition that exceeds the average values of the general population, the 2018 group slightly outperforming the 2016 group. However, the impact of the training they received is unknown because no measurements were taken prior to training. Better information could be obtained if the type and loads of training were also known to compare the results with other parameters, like body composition and oxygen consumption measurements before the start of training and subsequent follow up; this would be of great importance in future characterizations. 


\section{References}

1. Deborah Riebe; Jonathan K Ehrman; Gary Liguori; Meir Magal. ACSM's Guidelines for Exercise Testing and Prescription from American College of Sports Medicine. Editorial Philadelphia: Wolters Kluwer, 2018.

2. José López Chicharro, Almudena Fernández Vaquero. Fisiología del ejercicio. Tercera edición. Editorial Médica Panamericana; 2006.

3. W. Larry Kenney, Jack H. Wilmore, David L. Costill. Fisiología del Deporte y el Ejercicio. Quinta edición. Editorial Médica Panamericana; 2014

4. A A Narvani, P Thomas and B Lynn. Key topics in sports medicine. The United Kingdom by Routledge. The Taylor \& Francis e-Library, 2006.

5. Mauricio Serrato Roa. Medicina del deporte. Primera edición. Editorial de la Universidad del Rosario. 2008.

6. Everett A. Harman, David J. Gutekunst, Peter N. Frykman, Bradley C. Nindl, Joseph A. Alemany, Robert P. Mello, and Marilyn A. Sharp. Effects of two different eightweek training programs on military physical performance. J Strength Con Res. 2008. Volume 22(2)/524-534

7. Task Group 019. Report, R. T. O. T. Optimizing Operational Physical Fitness (Optimisation de l' aptitude physique opérationnelle ) Final Report of Task Group 019. (Vol. 323) 2009.

8. Ross R. Vickers, Jr. Amanda C. Barnard. Effects of Physical Training in Military Populations: A Meta-Analytic Summary. Naval Health Research Center. No. NHRC$11-17.2010$

9. Ejército Nacional de Colombia. Mejor equipo fuerzas comando 2018, categoría imagen institucional. Revista ejército, edición N. 199. 2018. https://dicoe.mil.co/revista_ejercito/revista/Revista_199/mejor-equipo-fuerzas-comando-2018.html

10. Dyrstad, Sindre M., Rune Soltvedt, and Jostein Hallén. Physical fitness and physical training during Norwegian military service. Milit Med. Vol 171.8 (2006): 736-741.

11. Matti Santtila, MSc Häkkinen Keijo, PhD Karavirta Laura, MSc Kyröläinen Heikki, PhD. Changes in Cardiovascular Performance during an 8-Week Military Basic Training Period Combined with Added Endurance or Strength Training. Milit Med, Volume 173, Issue 12, December 2008, Pages 1173-1179. 